\title{
E-government Implementation in Developing Countries: A Literature Review
}

\author{
DOI: https://doi.org/10.24297/ijct.v16i1.8371
}

\author{
Esam Elgohary \\ Institute of National Planning \\ Esam.elgohary@inp.edu.eg \\ ORCID ID: 0000-0003-0029-4769
}

\begin{abstract}
:
Recently, due to the numerous benefits of e-government implementation, so it becomes inevitable for both developed and developing countries. However, the benefits of implementing e-government face many challenges in developing countries. In this regard, many studies were conducted in several developing countries to determine the challenges to e-government implementation. This article conducted to review the most important studies in this regard and focus on the most common challenges to e-government implementation in developing countries. From the related literature, it clears that the most common challenges to e-government in developing countries are represented in five categories; technical challenges, organizational challenges, social issues, financial challenges and human challenges, such category include several factors. All these challenges have a direct or indirect effect on each other. So governments in developing countries have to focus on these five categories and seeking for handling them.
\end{abstract}

Keywords: E-government in developing countries, challenges of e-government, e-government obstacles, implementing e-government

\section{Introduction}

In recent years, the new developments in Information and Communication Technologies (ICT) support and enable organizations to deliver their services and information in novel ways. Governments have to keep up with these new developments especially after the emerging of e-government concept, that enabled governmental entities to deliver their services and information in more optimal ways -by using ICT- to their users (businesses, citizens and governmental organizations) (Andersen \& Henriksen, 2006). So, governments around the world have implemented e-government systems after recognizing its benefits as it leads to streamline and integrate workflows, enhance public service delivery and manage and processes data, information, human resource and financial resource (Liton \& Habib, 2015). It also can improve services, reduce costs, save time, and increase effectiveness and efficiency in the public sector (Alshehri \& Drew, 2010). Also, it helps the government to achieve accountability, transparency, accuracy, accessibility, and high quality in providing public services and information (Alkhwaldi et al., 2018). Thus, most countries have adopted e-government, with a variety in adoption rate between countries. Generally, developing countries are lagging in e-government adoption compared to developed countries (Furuholt \& Wahid, 2008).

However, many developing countries implemented e-government systems aiming at improving public sector services and delivering these services in an efficient and effective manner, only a limited percentage of them are successful cases (Sarrayrih \& Sriram, 2014). As, e-government represents economic, technical and social challenge (Signore et al., 2005), furthermore its implementation has usually challenged by a broad range of barriers (Bakunzibake et al., 2019). As well as, governments that tend to adopt e-government systems must consider the organizational, cultural, social, technological, and political issues which raise from e-government adoption (Alshehri et al., 2012). 
This paper studies the challenges of e-government implementation in developing countries, so it reviews the challenges that were mentioned in the previous studies on different countries and focused on the most common challenges in these countries.a

\section{E-government Definitions:}

In General, the increasingly use of ICTs in different fields has forced governments to adopt e-government systems; especially because the private sector adoption of ICTs which put the public sector under pressure. EGovernment concept refers to the use of technologies such as (internet, mobile computing, and wide area networks) by the government agencies to transform relationships with businesses, citizens and other government entities (Alshehri et al., 2012). Accordingly, government services can be provided through various methods such as; retailers, e-portals, banks, government, and private sectors (Sarrayrih \& Sriram, 2014).

E-government was defined as "government uses of information and communication technologies to offer for citizens and businesses the opportunity to interact and conduct business with government by using different electronic media such as telephone touch pad, fax, smart cards, self-service kiosks, e-mail / Internet, and Electronic Data Interchange (EDI)" (Almarabeh \& AbuAli, 2010).

As well as, the United Nation's, (2018) defined it as "The use of information and communication technologies (ICT) - such as Wide Area Networks, the Internet, and mobile computing - by government agencies."

Government interacting electronically with individuals and organizations in four forms as follows (Abdulkareem, 2015):

1. Government to Government (G2G): it is the backbone of e-government and refers to the processes of communication between different government entities and streamline processes.

2. Government to Business (G2B): the private sector gives significant attention for interactions with egovernment as e-government employs strategies that facilitate these interactions aiming to reduce costs through increases competition, improves procurement practices, and streamlines regulatory processes.

3. Government to Citizens (G2C): work on facilitating citizen interaction with government, which is the primary goal of e-government.

4. Government to Employee (G2E): it considered a subset of the G2G sector, and focuses on internal administrative activities.

\section{E-government Benefits:}

Furthermore, E-government implementation provides several benefits for both developed and developing countries as follows: (Alshehri et al., 2012)

- Reducing customers' and organizations' effort, time and costs

- Improving service delivery and citizens' satisfaction through the better understanding of the users' requirements, which seamless online services

- Increasing users' internet knowledge, ICT skills, and computer usage

- Creating work opportunities and new business

- Improving government agencies efficiency in the data processing

- Reducing data duplication by sharing information and ideas between all government organizations and 
departments which enable to build one mega data base.

- Improving efficiency through promoting productivity gains and assisting the government in achieving the objectives of economic policy

- Attempt to building trust between governments and citizens by involving citizens in the policy process, improving government transparency, accuracy, and accountability

- Decreasing corruption and increasing equity between all citizens.

- Delivering government services through online systems helps citizens to access it easily and from any place, as well as ensuring the services availability $24 / 7$.

\section{Related Studies:}

Despite the benefits of e-government, it has yet to affect the vast majority of governments in developing countries, as the e-government initiatives face serious challenges (Qaisar \& Ali khan, 2010).

The variety and complexity of e-government initiatives imply the existence of a wide range of challenges and barriers to its implementation and management. Thus, there are many pieces of literature that enumerated numerous challenges and issues that can delay the progress of e-government implementation (Alshehri et al., 2012).

In this regard, there are many studies that discuss the most important e-government challenges in developing countries some of them discussed these challenges generally in developing countries, and others applied their study on a specific country such as; Bangladesh, Jordan, Ghana, India, Nigeria, Iraq, Libya, Uganda, Kenya, and Zambia. The most important of these studies are presented as follows:

Gyamfi et al., (2019), opine that the problems and challenges that impede the success of e-government projects in developing countries are very crucial. They revealed in their study addressed "Assessing the Factors Affecting the Implementation of E-Government and Effect on Performance of DVLA," that the problems and challenges that impede the success of e-government projects in developing countries are; lack of ICT infrastructure, interruption of electricity power supply, security threats and financial constraints. The results of this study are all in consonance with the outcome of other studies; Mpinganjira (2013), Acheampong (2012) and Alam (2012).

From Sarker, et al. (2019) study about "Challenges and Opportunities for Information Resource Management for E-Governance in Bangladesh", it reveals that the main barriers to e-government implementation are; cultural and social constraints, constraints related to political consensus and Security of Data, human resources constraints, Digital Divide constraints, and Infrastructural Development constraints.

Alkhwaldi et al., (2018) in his study "Analysis of Cloud-Based E-government Services Acceptance in Jordan: Challenges and Barriers" has classified e-government challenges as follows:

1. Technological challenges: include IT infrastructure, security, availability, accessibility, and website design.

2. Human aspects: include lack of awareness and ICT skills.

3. Social Challenges: include culture.

4. Financial challenges: include high cost and lack of budget.

While, a study conducted by Amegavi, et al., (2018) addressed "The dynamics of e-government enactment in a developing country public sector organization: evidence from Ghana", revealed that Human resource, Low ICT 
literacy, Financial resources, unreliable internet connectivity, Inadequate ICT equipment and the role of leadership are the barriers of successful implementation of e-government.

Gupta, et al., (2018), mentioned in their study "Analyzing the Interaction of Barriers in E-Governance Implementation for Effective Service Quality: Interpretive Structural Modeling Approach", a number of 14 barriers to implementing e-government those are; Lack of inter- and intra-organizational collaboration, Lack of feedback-based learning loops, Lack of citizen engagement, Lack of top management commitment, Lack of political will, Resistance to change, Lack of trust on e-governance, Lack of clarity about roles and responsibilities, Inadequate planning for project sustainability, Unrealistic time frames for implementation, Rigid process in government system, Inadequate infrastructure, Ignorance of stakeholders' concerns, Insufficient requirement analysis

Ajibade, et al. (2017) and (Abdulkareem, 2015) illustrated in their studies that conducted on Nigeria in order to determine the challenges impeded the success of e-government implementation, that challenges to implementing e-government in Nigeria are; Infrastructural Deficit, Digital Divide, Incessant Power Failure, low ICT literacy level, privacy and security challenges, and theft and vandalism of ICT equipment.

Mohammed et al. (2016) conducted a study addressed "E-government and its Challenges in Developing Countries: Case Study Iraqi E-government" this study aims at increasing the awareness of e-government for employees, government, private sectors, and citizens by identifying the e-government in Iraq and explain its challenges. They found that the e-government implementation challenges in Iraq represented in five categories, those are; Politics, organizational, human capability, technical and security. They also illustrated that each of these challenges has many factors that influence positively or negatively on e-government to e-government these factors are limited budget, bureaucracy, slow process for decision making, rules and regulations, transparency and monitoring, top management support, trust, and validity organizational structure, reliability of information, as well as lack of technical person, incompatibility of technician staff, resistance for new technology, threat to personal freedoms, illiteracy computer \& internet, interoperability, lack of awareness, and lack of devices and infrastructure.

Another study conducted by Amagoh, (2016) on Nigeria to assess e-government illustrate that the challenges to e-government are, high rate of corruption, lack of basic infrastructures, and a large digital divide

Ahmed et al. (2013), stated in their study "E-Government Services Challenges and Opportunities for Developing Countries: The Case of Libya," that the main challenges to e-government implementation represented in technical challenges, infrastructure challenges, cultural and social issues.

Nabafu \& Maiga, (2012), conducted a study on Uganda addressed "A model of success factors for implementing local e-government in Uganda," determined that the e-government in Uganda has faced challenges with building ICT infrastructure, financial resources, awareness, and social-political factors

While, Alshehri et al., (2012) and Alshehri \& Drew, (2010), have categorized E-government challenges into four categories as follows:

1. Technical Barriers: include ICT infrastructure, privacy, and security.

2. Organizational Barriers: include top management support, resistance to change to electronic ways, lack of partners and collaboration, lack of qualified personnel and training, and policy and regulation issues.

3. Social Barriers: include digital divide and culture

4. Economical or Financial barriers: include High cost and lack of budget 
Nabafu \& Maiga, (2012) determined that challenges to e-government in Kenya were represented in poor information infrastructure, lack of ICT policies, entrenched graft, inadequate human skills, digital divide, and IT illiteracy.

Bwalya, (2009) stated that implementation of e-government in Zambia had faced many challenges such as; lack of ICT infrastructure, resistance by employees and citizens, lack of IT skills and lack of financial resources.

A study on Sub-Saharan Africa conducted by (Mutula, 2008) addressed "Comparison of sub-Saharan Africa's egovernment status with developed and transitional nations" revealed that infrastructure, skill factors, legal and policy are all the major barriers of e-government in Sub-Saharan Africa

As well as (Furuholt \& Wahid, 2008) demonstrated that e-government challenges seem to fall into three categories:

1. Management, including strategic issues, change management, political leadership, institutionalizing, and continuous monitoring and evaluation of the projects.

2. Infrastructure, including ICT infrastructure, legislation, and financial resources

3. Human factors, including competence and skills, training, and trust.

Refined, 2006, mentioned in his study "Towards e-government in a Sub-Saharan African country: Impediments and initiatives in Nigeria" that inadequate infrastructural support, poor organizational skills attitudinal problems, and poor human capital resources are the challenges that Nigeria faces in implementing e-government system.

Also, (Signore et al., 2005) classified e-government challenges as follows:

1. Technical issues: including interoperability, privacy, security, and Multimodal interaction.

2. Economic issues: including maintainability, reusability, and portability.

3. Social issues: including accessibility, usability, and acceptance.

\section{E-government Challenges:}

From the discussion of previous studies of challenges facing the success of e-government implementation in developing countries it can be noticed that the most common challenges are represented in five categories; technical challenges, organizational challenges, social issues, human issues, and financial challenges.

\section{Technical Barriers:}

The e-government implementation in developing countries faces some technological difficulties such as lack of ICT infrastructure among departments and entities. As well as privacy, security, availability, and accessibility issues, which are critical barriers in implementing e-government systems (Alshehri et al., 2012).

\subsection{ICT Infrastructure}

Implementing a successful e-government system and delivering services require a strong and effective infrastructure of technology. Also, the structure of the capacities of various infrastructures and how they are capitalized with an integrated focus, have influenced the successful e-government implementation (Brown \& Thompson, 2011). The technology infrastructure composed of hardware and networks such as local area network (LAN), WAN network (Internet, Extranet and Intranet), and other technical components, as well as databases and operating systems (Alkhwaldi, 2018). 
In developing countries ICT infrastructure is considered one of the main challenges for e-government, where, many of these countries are not able to deploy the appropriate ICT infrastructure as they suffering from digital divide, that refers to the "large differences in the level of access to the Internet and therefore ability to benefit from e-government" (Rose \& Grant, 2010). This lack of ICT infrastructure in developing countries often impedes the successful implementation of e-government (Alkhwaldi, 2018). Also, using and utilizing from e-government applications need E-readiness, ICT literacy, and access to the internet and electronic service channels. The weakness of these factors in addition to limited bandwidth and high cost of using new technologies, influence IT infrastructure, as they represent challenges to it.

Consequently, governments have to work closely with the private sector to establish a modern ICT infrastructure to provide access opportunities to disconnected individuals.

\subsection{Privacy}

Privacy is a critical challenge in e-government implementation, as it refers to "the guarantee of an appropriate level of protection regarding information attributed to an individual" (Alshehri et al., 2012), and it requires both policy and technical responses when addressing the privacy issue in an e-government context.

However, the importance of citizens' confidence in the careful handling and privacy of any personal information that shared with government agencies (Weerakkody et al., 2011), citizens, especially in developing countries, are concerned about information sharing, website tracking, mishandling of private information and the egovernment ability to monitor and invade their privacy. So, governments need to deal effectively with privacy issues in e-networks to increase citizens' confidence in the use of e-government services (Lean et al., 2009). As well as, governments are obliged to ensure citizens' rights regarding privacy, processing, and collecting personal data for legitimate purposes only (Sharma \& Gupta, 2003), consequently, they must give the priority to privacy and confidentiality issues when establishing and maintaining websites in order to ensure the secure collection of data (Almarabeh \& AbuAli, 2010). Since it is difficult to interject the privacy protections once an e-system has been built, the privacy considerations must be included in the planning and design of e-government systems. The comprehensive privacy policy should specify the citizens' rights to privacy and mandate that personal data are collected and processed only for legitimate purposes (Shareef et al., 2011).

\subsection{Security}

There is a consensus on considering security issue for both citizens and governments as one of the critical factors for the e-government system implementation around the world (Almarabeh \& AbuAli, 2010). Security can be defined as "the protection of information and systems against accidental or intentional disclosure to unauthorized access, or unauthorized modifications or destruction" (Layton, 2007). Consequently, it refers to the protection of assets, information systems, and the control of access to the information itself (Lean et al. 2009), as well as security can have technical or non-technical issues, as the non-technical issues have more influence in the developing countries.

The security policies and standards which meet citizen expectations represent a vital component in addressing the concerns of the trust relationship between citizens and government (Colesca, 2009).

However, information security is costly, it is a necessary part of e-government, and it involves the protection of data, in addition to training and oversight of personnel, integrating of software and hardware, service continuity, which is essential to availability and delivery of services, and citizens' confidence and trust establishment.

Security cover of many elements such as computer security documents security, network security, and confidentiality of personal data (Smith \& Jamieson, 2006), as well as e-infrastructure protection and maintenance in the form of firewalls and limits to those who have access to the data. Moreover, the security technology usage includes digital encryption, signatures, bank account numbers, credit card numbers, passwords, user IDs, and other transmitted and stored data electronically over the internet; these can aid in the security goals achievement in 
e-government applications (Weerakkody et al., 2011). Also, security systems involve continuous protection against the increasing danger of viruses and worms.

Users need to be educated on the importance of security measures, such as private passwords, to ensure their protection. (Reddick \& Frank 2007) point out three keys that affect the success of security as follows:

- Continuous improvement and upgrades in an attempt to stay ahead of criminals.

- $\quad$ Security must be visible and foreboding to deter possible criminals.

- The fact that must be accepted is that no security system is perfect and that all systems can eventually be overcome.

Hence, government organizations those are responsible for the maintenance, collection, and distribution of confidential or sensitive information, have to consider security methods for collected information as well as for their websites. Also, a top priority should be given for authority and an infrastructure encryption system (Colesca, 2009).

\subsection{Availability:}

Availability refers to "the number of e-services that are available for the citizens 24/7" (Almarabeh \& AbuAli, 2010). As well as it improves the citizens' satisfaction of the e-government system due to its influence on service quality (Rehman \& Esichaikul, 2011). So the availability of services is crucial for e-government success. Consequently, governments have to give attention to improving the available e-government services and work on increasing the amount of these services.

\subsection{Accessibility.}

Accessibility refers to "how citizens' obtain online government services and information through multiple echannels." The presence of e-channels enables all types of citizens to access the e-government services despite their residence place, religion or even disabilities, so, service accessibility can be proposed as an important predictor to establish "citizen-centric" e-government services (Alomari et al., 2012).

Due to the vital rule of availability and accessibility in e-government success, government agencies should ensure the availability and accessibility of their web services to all stakeholders from different locations (Alkhwaldi et al., 2018).

\section{Organizational Barriers}

Organizational challenges include leader and top management support, resistance to change, lack of partnership and collaboration, lack of qualified personnel and training, and policy and regulation issues.

\subsection{Leader and Top management support}

The top management support is crucial in adopting any new innovation, and plays a significant role in adopting and implementing e-government (Al-Khafaji, et al., 2012), as it refers to "the commitment from top management to provide a positive environment that encourages participation in e-government applications" (Hussein et al., 2007). Thus, the successful implementation of e-government needs support from the highest level of government.

Similarly, leadership is one of the main driving factors in every new and innovative project or initiative, so it is necessary for e-government implementation. Hence, leadership involvement and clear lines of accountability for improving management are important to gather the necessary resources for improving management, 
overcome the natural resistance to organizational change and build and maintain the organization-wide commitment to new methods of conducting e-government systems (Almarabeh \& AbuAli, 2010). The involvement of high-level leadership and integrated vision of IT, are vital to the acquisition of necessary resources, vertical planning of e-government, the motivation of officials, interagency and ministry co-ordination and support of dealings with stakeholders and external partners as well as, it is observed in developing countries that e-government developing is driven by political leadership and an integrated vision of IT.

Therefore, the government has to educate the potential government managers, administrators and leaders in planning and managing ICTs across all public sectors, focusing on effective delivery, access opportunity and economic development of public information and services (Olasina, 2014).

\subsection{Resistance to change to electronic ways}

E-government means transformation from work manual methods to electronic methods, thus creates a new advanced environment that is completely different from what has been used in the traditional government departments (Alshehri \& Drew, 2010). These changes lead many employees to consider e-government revolution as a threat for their future rather than an opportunity, in other words, "they are afraid to lose their jobs," so, these employees tend to resist these changes, which represent a barrier for public offices modernization and for implementing change initiatives. This resistance to change resulted from shifting from a known organizational structure to a new one as well as unqualified employees for using and utilizing the information technologies (Al-Khafaji et al., 2012), as well as the income, education, and age factors. Accordingly, resistance to change is considered as one of the organizational challenges of implementing e-government. It is noticeable that the e-government system does not face only an internal resistance from employees, but it also may face resistance by citizens that lead to negative outcomes regarding e-government participation (Alzahrani \& Goodwin, 2012). This resistance to change, whether internal or external, represents a risk as it may lead to the collapse of e-government systems. So, e-government leaders have to identify the sources of resistance and create a plan in order to treat them by retraining employees and developing their skills to be able to deal with the implemented information system (Alshehri \& Drew, 2010), as well as regarding the resistance by citizens, governments need to improve their social life and establish a knowledge-based society in an effort to change the IT-culture of their citizens (Alkhwaldi, 2018).

\subsection{Lack of partnership and collaboration}

Collaboration and cooperation between public and private organizations play a critical role in the success of egovernment implementation process (Altameem et al., 2006). The government should encourage all sectors to participate in e-government implementation and development. As, they provide government with skills and capabilities, plans, resources and experiences that it lacks, for instance, "the ICT private sector is able to support the government with technical skills and infrastructure; meanwhile, universities will provide the required staff, learning, and training courses for government staff and citizens, and other government departments and agencies can contribute in data and information flow and knowledge sharing for problem-solving of similar tasks or processes and so on" (Alshehri, et al., 2012).

Accordingly, the lack of collaboration and cooperation between organizations and e-government is one of the main factors in e-government failures (Almarabeh \& AbuAli, 2010).

Collaboration and cooperation are not simple to realize, especially citizens distrust their governments; particularly those have a history of political instability, large-scale corruption, or dictatorship. So, the government must do efforts to build citizens' trust in their government to ensure the public and stakeholders participation in e-government. As well as the government must play the role of facilitator and encourage the private sector to participate in e-government development and implementation (Alshehri et al., 2012).

\subsection{Lack of qualified personnel and training}


A successful e-government implementation needs appropriate skills, as it requires technical skills for design, implementation, installation, and maintenance of ICT infrastructure, in addition to skills for using and managing online functions, processes, and customers (Alshehri et al., 2012).

Lack of ICT skills is a particular problem in developing countries due to the constant lack of qualified staff and inadequate training of human resources (Mahmood et al., 2019). So, it is considered one of the major challenges to e-government initiatives. Consequently, governments have to develop human capital, by providing knowledge management initiatives that focus on seminars, staff training, and workshops to create and develop the basic skills of e-government usage (Abdulkareem, 2015). It is important for governments to focus on training, education programs, and learning skills to enhance e-government projects and fulfill the full economic benefits of ICT (Gyamfi et al., 2019)

\subsection{Policy and regulation issues}

Implementing e-government functions and principles requires a range of new laws, policies, rules, and government changes to address electronic activities that include; electronic archiving, the transmission of information, electronic signatures, data protection, copyright issues, intellectual property rights and computer crime, (Almarabeh \& AbuAli, 2010). As dealing with e-government requires signing a digital agreement or a contract that must be recognized and protected by a formalized law, which is specified to protect these activities (Alshehri et al., 2012).

Furthermore, the laws of e-government and e-business are not yet available in many countries (Dawes, 2008), so during e-government implementation policy makers must consider the impact of law and public policy (Mahmood, et al., 2019) as well as, they have to establish protections and legal reforms in order to ensure the security, privacy, and legal recognition of electronic signatures and electronic interactions (Alshehri et al., 2012).

\section{Social Barriers}

Social issues to the e-government implementation are concerned with the social implications of new IT as well as the usability by a large variety of people. The social aspect includes many challenges such as; culture, and the digital divide (Alshehri et al., 2012).

\subsection{Digital Divide}

Successful e-government implementation requires the ability to use computers and the internet, so lack of these skills represents a barrier to e-government (Mahmood et al., 2019). The digital divide is "the gap in opportunity between those who have access to the Internet and those who do not" (Alshehri et al., 2012). It results in developing countries from low literacy, lack of infrastructure, slow adoption of technology, high corruption, massive poverty and access to modern technology such as; internet, mobile phones, and computers (Ajibade et al., 2017 and Sarker, et al., 2019).

In developing countries, not all citizens have equal access to the internet, whether due to a lack of necessary skills, financial resources, or other reasons. Therefore, governments should provide training in computer basics and internet skills to their citizens and employees so that they can participate in e-government development applications (Alshehri, et al., 2012). Also, the gap between those who have access to the internet and data services and those who do not can be addressed by making internet services available (Ajibade et al., 2017). A survey conducted by (United Nations, 2018) clears that the increase of digital divide necessarily increases the cost of technical barriers to e-government.

\subsection{Culture}

Cultural implications of new technologies are one of the main barriers to e-government implementation (Ajibade et al., 2017). Culture includes several principles, such as society, religion, beliefs, language, values, education, 
characteristics, and behaviors (Alshehri et al., 2012). Therefore, culture plays a significant role in how policy makers and citizens use new technologies and online systems (Choudrie et al., 2010). Individual's culture plays a significant role in resistance to change and slow adoption of new technologies (Mahmood et al., 2019), thus it has negatively affected the acceptance and adoption of e-government system. Consequently, changing the major culture of society is necessary to achieve successful e-government.

\section{Financial Barriers}

E-government implementation is very expensive because of the high cost of computer systems implementation and maintenance, which put many countries in front of funding e-government programs dilemma. The egovernment implementation cost includes; high cost of systems software, hardware and maintenance, training, and education, so lack of money is the most significant barrier to the e-government implementation process (Alshehri et al., 2012). According to (Brown \& Thompson, 2011), lack of financial support for capital investment in new ICT systems in developing countries is the major obstacle to e-government. To address the financial barriers, public administrations must guarantee long-period financial support for the e-government.

\section{Human challenges}

Most developing countries suffer from the challenge of inadequate ICT human resource in their effort to develop e-government programs (Olasina, 2014). As well as, many e-government projects in most African countries have failed because of the incompatibility between adopted technologies and human skills and capacities to manage them (Asogwa, 2013; Eze et al., 2013).

According to Alkhwaldi, et al. (2018) "Once the people have the infrastructure to go online, they need the awareness, skills and online content to motivate their access," so it clears that lack of awareness and ICT skills to represent barriers to e-government initiatives.

\subsection{Lack of awareness.}

Generally, in developing countries, citizens have limited awareness of e-government services and their benefits (Weerakkody et al., 2011). This lack of awareness is considered one of the barriers to successful e-government adoption (Rana et al., 2013). Awareness refers to "the person understands of others' activities, which yields to a context for his activities" (Alateyah et al., 2013).

Lack of awareness causes the low rates of citizens' participation in e-government projects and its failure (Rehman \& Esichaikul, 2011). Therefore, governments should work on increasing the citizens' awareness by launching attractive awareness campaigns to promote new services of e-government and achieve the success of egovernment implementation.

\subsection{ICT skills.}

The required ICT skills to use e-government systems by citizens are Information security literacy and ICT literacy. The lack of these skills, particularly in developing countries is a crucial challenge to e-government initiatives (Odat, 2012). ICT Literacy is defined as "the ability to use information technology tools, communications tools, ICT applications to access, use, integrate, assesses, and create information in order to participate in an Information technology society" (Katz et al., 2009), so it indicates people who are unable to use ICT due to the lack of computer knowledge and education (Almarabeh \& AbuAli, 2010).

While information security literacy means "the scarcity of basic knowledge about secure online practices"( Furnell \& Moore, 2014). 
So, governments needed to provide security, essential computer, and internet skills to their citizens to improve their participation in e-government.

\section{Conclusion:}

E-government is crucial for every government in both developed, and developing countries as it is the government means to keep up with the technological developments. In conclusion, after reviewing related literature to e-government challenges in developing countries, it can be concluded that the most important

e-government challenges can be classified into five categories those are; technical challenges, organizational challenges, social issues, financial challenges, and human challenges. Such challenge includes several elements as follows:

Technical challenges include; lack of ICT infrastructures, privacy, security issues, availability and accessibility.

Lack of ICT infrastructures is considered the fundamental element of implementing e-government as it consists of hardware and software. Consequently, it is responsible for work processes, and information flows, and so, it is impossible to implement e-government system without ICT infrastructures, as well as ICT infrastructure is engaged with services availability $24 / 7$ and the citizens' ability to access to the internet and deal with information technology. Privacy and security are integrated issues, as privacy relating to the citizens' privacy of information, while security dealing with regulations which ensure the secure of interactions.

Organizational challenges include; leader and top management support, resistance to change, lack of partnership and collaboration, lack of qualified personnel and training, and policy and regulation issues. It clears that the lack of ICT qualifications and the employees' fear of losing their jobs create the resistance to change as well as the absence of leader and top management support

Social issues include; culture and the digital divide. It clears that the citizens' culture consists of society religion, beliefs, language, values, education, characteristics, and behaviors, plays an important role in resistance to change and slow adoption of new technologies as well as digital divide results from low literacy, lack of infrastructure, slow adoption of technology, high corruption, massive poverty and access to modern technology.

Financial challenges are the major challenge to e-government implementation as the funding lack affect the availability of a strong ICT infrastructure, a strong security system, and effective training programs for employees because of their high cost

Human challenges include; lack of awareness and ICT skills. It clears that the citizens' awareness of e-government initiatives is important to encourage them to interact with e-government systems as well as ICT skills include Information security literacy and ICT literacy which determined the citizen's ability to use ICTs and interact with e-government system.

Finally, it clears that all challenges to e-government implementation in developing countries have a direct or indirect effect on each other.

\section{Recommendations for e-governments in developing countries:}

- Governments are recommended to collaborate with the private sector to ensure funding resources for egovernment implementation.

- Governments must implement and develop a strong ICT infrastructure.

- Governments have to provide training programs to their employees and citizens to increase their awareness about e-government importance and benefits as well as educate them the ICT literacy. 
- Governments must care about the laws and regulations that organize e-government transactions, and ensure the system secure and citizens' privacy

- Governments have to work on changing society culture to eliminate resistance to change.

- The government must qualify the upcoming leaders and managers to be able to manage and improve egovernment. The government have to work on acquiring citizens' trust in e-government

\section{References}

1. Andersen, K. V., and Henriksen, H. Z. (2006). "E-government maturity models: Extension of the Layne and Lee model," Government Information Quarterly, Vol.23, No.2, pp. 236-248

2. Sarrayrih, M. \& Sriram, B. (2014). Major challenges in developing successful e-government: A review on the Sultanate of Oman. Journal of King Saud University - Computer and Information Sciences, Vol. 27, pp. 230235

3. Bakunzibake, P., Grönlund, A., Klein, G. O. (2019). Organizational Challenges in the Implementation of 'onestop' e-Government in Rwanda. Electronic Journal of e-Government, Vol.17, No.1, pp. 1-19

4. Altameem, T., Zairi, M., \& Alshawi, S. (2006, November 19-21) Critical success factors of e-government: A proposed model for e-government implementation. Proceedings of the International Conference on innovations in Information Technology (IIT 2006), Dubai, UAE.

5. Alshehri, M. \& Drew, S. (2010). Implementation of e-Government: Advantages and Challenges. In proceedings of IASK E-ALT2010 CONFERENCE. Pp.79 - 86

6. Alshehri, M., Nguyen, A. \& Drew, S. (2012). Using the UTAUT Model to Determine Factors Affecting Acceptance and Use of E-government Services in the Kingdom of Saudi Arabia. Unpublished doctoral dissertation, School of Information and communication technology, Griffith University.

7. Alkhwaldi, A., Kamala, M., \& Qahwaji, R. (2018). Analysis of Cloud-Based E-government Services Acceptance in Jordan: Challenges and Barriers. Journal of Internet Technology and Secured Transactions (JITST), Volume 6, No.2, pp. 556-568

8. Liton, S. \& Habib, A. (2015). Analyzing Challenges and Opportunities for the Implementation of EGovernment in Bangladesh. Global Journal of Computer Science and Technology: Interdisciplinary. Vol.15 No.1

9. Signore, O., Chesi, F. \& Pallotti, M. (2005). E-government: challenges and opportunities. In Proceedings of CMG Italy - XIX Annual Conference 7-9 June 2005 Florence, Italy

10. Furuholt, B. \& Wahid, F. (2008). E-government Challenges and the Role of Political Leadership in Indonesia: the Case of Sragen. Proceedings of the 41st Hawaii International Conference on System Sciences

11. Reddick, C. G., \& Frank, H. A. (2007). The perceived impacts of e-government on U. S. cities: A survey of Florida and Texas city managers. Government Information Quarterly, 24(3), 576-594.

12. Nabafu, R., and Maiga, G. (2012). A model of success factors for implementing local e-government in Uganda. Electronic Journal of e-Government, Vol.10, No.1, pp. 31-46.

13. Almarabeh, T., and AbuAli, A. (2010). A General Framework for E-Government: Definition Maturity Challenges, Opportunities, and Success. European Journal of Scientific Research, 39, 1, 29-42 
14. United Nations. (2018). E-government Survey: Gearing E-government to Support Transformation towards Sustainable and Resilient Societies. United Nations, New York.

15. Bwalya, K.J. (2009). Factors Affecting the Adoption of e-Government in Zambia. The Electronic Journal of Information Systems in Developing Countries, 38(1), pp.1-13.

16. Choudrie, J., Umeoji, E., \& Forson, C. (2010). Diffusion of e-government in Nigeria: A qualitative study of culture and gender. Pre-ICIS SIG Global Development Workshop, Saint Louis, Missouri, USA.

17. Gyamfi, G.D., Gyan, G., Ayebea, M., Nortey, F. \& Baidoo, P. (2019). Assessing the Factors Affecting the Implementation of E-Government and Effect on Performance of DVLA. International Journal of Electronic Government Research, Vol. 15, No. 1, pp. 47-61

18. Abdulkareem, A.K. (2015). Challenges of E-Government Implementation in the Nigerian Public Service. JOURNAL OF CREATIVE WRITING, Vol. 1, No. 4, pp. 45-56

19. Alam, M. (2012). E-Governance in Bangladesh: Present Problems and Possible Suggestions for Future Development. International Journal of Applied Information Systems, Vol.4, No.8, pp. 21-25. DOI:10.5120/ijais12-450804

20. Achampong, E. K. (2012). The State of Information and Communication Technology and Health Informatics in Ghana. Online Journal of Public Health Informatics. DOI:10.5210/ojphi.v412.4191

21. Mpinganjira, M. (2013). E-government project failure in Africa: Lessons for reducing. African Journal of Business Management, Vol.7, No.32, pp.3196-3201. DOI:10.5897/AJBM12.1093

22. Dawes, S. S. (2008). The evolution and continuing challenges of e-governance. Public Administration Review, Vol.68, N.1, S86-S102.

23. Ajibade, O., Ibietan, J. \& Ayelabola, O. (2017). E-Governance Implementation and Public Service Delivery in Nigeria: The Technology Acceptance Model (TAM) Application. Journal of Public Administration and Governance, Vol. 7, No. 4, pp. 165-174.

24. Mahmood, M., Weerakkody, V., \& Chen, W. (2019). The influence of transformed government on citizens trust: Insight from Bahrain. Information Technology for Development, Vol.25, No.2, 275-303. DOI:10.1080/0268110 2.2018.1451980

25. Mohammed, M.A., Aboobaider, B.M., Ibrahim, H., Abdullah, H.A., Ali, M.H., Jaber, M., and Shawkat, A. (2016). E-government and its Challenges in Developing Countries: Case Study Iraqi Government. The Social Sciences, Vol.11, No.17, pp.4310-4319

26. Olana, G. (2014) 'E-parliament services as tools for anti-corruption and transparency', International Journal of Electronic Governance, Vol. 7, No. 1, pp.27-55, http://www.inderscience.com/link.p hp?id=65083

27. Amiga, G.B., Bawole, J.N. \& Buabeng, T. (2018). The dynamics of e-government enactment in a developing country public sector organization: evidence from Ghana. Int. J. Electronic Governance, Vol. 10, No. 1, pp. 74-92

28. Eze, S.C., Awa, H.O., Okoye, J.C., Emecheta, B.C. and Anazodo, R.O. (2013) 'Determinant factors of information communication technology (ICT) adoption by government-owned universities in Nigeria: a qualitative approach,' Journal of Enterprise Information Management, Vol. 26, No. 4, pp.427-443. 
29. Asogwa, B.E. (2013)'Electronic government as a paradigm shift for efficient public services: opportunities and challenges for Nigerian government', Library Hi-Tech, Vol. 31, No. 1, pp.141-159.

30. Ahmed, M., Mehdi, O., Moreton, R. \& Elmaghraby, A. (2013). E-Government Services Challenges and Opportunities for Developing Countries: The Case of Libya. 2nd International Conference on Informatics and Applications, ICIA, pp. 133-137 DOI: $\underline{10.1109 / I C o l A .2013 .6650243}$

31. Gupta, A., Suri, P., Singh, R. (2018). Analyzing the Interaction of Barriers in E-Governance Implementation for Effective Service Quality: Interpretive Structural Modeling Approach. Business Perspectives and Research 1-17 DOI: 10.1177/2278533718800562

32. Sarker, M.N., Wu, M., Liu, R. \& Ma, C. (2019). Challenges and Opportunities for Information Resource Management for E-Governance in Bangladesh. Chapter 53, pp. 675-688, Proceedings of the Twelfth International Conference on Management Science and Engineering Management, Lecture Notes on Multidisciplinary Industrial Engineering, https://doi.org/10.1007/978-3-319-93351-1_53

33. Mutula, S.M., 2008. Comparison of sub-Saharan Africa's e-government status with developed and transitional nations. Information Management \& Computer Security, Vol.16, No.3, pp.235-250.

34. Amagoh, F. (2016). An Assessment of E-Government in a West African Country: The Case of Nigeria. In Politics and Social Activism: Concepts, Methodologies, Tools, and Applications (pp. 823-843).DOI: 10.4018/978-1-4666-9461-3.ch042.

35. Ifinedo, P. (2006). Towards e-government in a Sub-Saharan African country: Impediments and initiatives in Nigeria. Journal of E-Government, Vol.3, No.1, pp.3-28.

36. Brown, H. D., \& Thompson, S. (2011), Priorities, policies, and practice of e-government in a developing country context: ICT infrastructure and diffusion in Jamaica. European Journal of Information Systems, Vol.20 No.3, 329-342.

37. Rose, W. R., \& Grant, G. G. (2010). Critical issues about the planning and implementation of e-government initiatives. Government Information Quarterly, Vol.27, No.1, pp.26-33.

38. Qaisar, N., \& Khan, H. G. A. (2010). E-government challenges in the public sector: A case study of Pakistan. IJCSI International Journal of Computer Science Issues, Vol.7, No.5, pp.310-317.

39. Alateyah, S. A., Crowder, R. M., and Wills G. B.,(2013)."Identified factors affecting the citizen's intention to adopt e-government in Saudi Arabia,", p. 904: World Academy of Science, Engineering, and Technology (WASET)

40. Rana, N. P., Dwivedi, Y. K. and Williams, M. D. (2013)."Analyzing challenges, barriers and CSF of egov adoption," Transforming Government: People, Process and Policy, vol. 7, No. 2, pp. 177-198,

41. Weerakkody, V., El-Haddadeh, R., \& Al-Shafi, S. (2011). Exploring the complexities of e-government implementation and diffusion in a developing country: Some lessons from the State of Qatar. Journal of Enterprise Information Management, Vol.24, No.2, pp.172-196.

42. Lean, O. K., Zailani, S., Ramayah, T., \& Fernando, Y. (2009). Factors influencing intention to use e-government services among citizens in Malaysia. International Journal of Information Management, Vol.29, No.6, pp.458475.

43. Sharma, S., \& Gupta, J. (2003). Building blocks of e-government: A framework. Journal of Electronic Commerce in Organizations, Vol.1, No.4, pp. 1-15. 
44. Shareef, M. A., Kumar, U., \& Kumar, V. (2011). E-government development: Performance evaluation parameters. In M. Shareef, V. Kumar, U. Kumar, \& Y. Dwivedi (Eds.), Stakeholder Adoption of E-Government Services: Driving and Resisting Factors (pp. 197-213). Hershey, PA: Information Science Reference. DOI:10.4018/978-1-60960-601-5.ch010.

45. Layton, T. (2007). Information security: Design, implementation, measurement, and compliance. Boca Raton, FL: Auerbach Publications.

46. Colesca, S. (2009). Increasing e-trust: A solution to minimize risk in e-government adoption. Journal of Applied Quantitative Methods (JAQM), Vol.4, No.1, pp. 31-44.

47. Smith, S. \& Jamieson, R. (2006). Determining key factors in e-government information system security, Information Systems Management, Vol.23, No.3, pp. 23-32.

48. Rehman, M. \& Esichaikul, V. (2011). "Factors influencing the adoption of e-government in Pakistan," in EBusiness and E-Government (ICEE), International Conference, pp. 1-4: IEEE.

49. Alomari, M., Woods, P. \& Sandhu, K. (2012). "Predictors for e-government adoption in Jordan: Deployment of an empirical evaluation based on a citizen-centric approach," Information Technology \& People, vol. 25, no. 2, pp. 207-234,

50. Hussein, R., Karim, N. S. A., Mohamed, N., \& Ahlan, A. R. (2007). The influence of organizational factors on information systems success in e-government agencies in Malaysia. Electronic Journal on Information Systems in Developing Countries, Vol.29, No., pp.1-17.

51. Al-Khafaji, N.J., Shittuline, A.J. \& Osman, W.R. (2012). The Effect of Resistance to Change in the Application of e-Government in Iraq, 2012 Tenth International Conference on ICT and Knowledge Engineering pp. 99103: IEEE.

52. Alzahrani, M.E. \& Goodwin, R. D. (2012). "Towards a UTAUT-based Model for the Study of eGovernment Citizen Acceptance in Saudi Arabia," World Academy of Science, Engineering and Technology, International Journal of Social, Behavioral, Educational, Economic, Business and Industrial Engineering, vol. 6, no. 4, pp. 376-382.

53. Odat, M. (2012). E-Government In Developing Countries: Framework Of Challenges And Opportunities, Journal of Theoretical and Applied Information Technology, Vol. 46 No.2, pp. 1013-1021,

54. Furnell, S. \& Moore, L. (2014). Security literacy: the missing link in today's online society?. Computer Fraud \& Security, vol. 2014, no. 5, pp. 12-18. 